\title{
Determination of Formaldehyde in Human Tissue through Derivatization with 2,4-Dinitrophenylhydrazine by Square Wave Polarography Method
}

\author{
Bilal Yilmaz, Kaan Kucukoglu, Ali Asci, and Mevlut Albayrak
}

\begin{abstract}
The polarographic behaviour of formaldehyde (FA) was studied using cyclic and square wave polarography (SWP) methods. FA was derivatized with 2.4-dinitrophenylhydrazine (DNPH). The influence of several variables (including nature of the buffer, $\mathrm{pH}$, concentration, scan rate, drop size, etc.) was examined in SWP method for FA. The best SWP responses were obtained in acetate buffer $\mathrm{pH}$ 5.0. The peak currents were measured with a static mercury drop electrode at $-0.16 \mathrm{~V}$ versus $\mathrm{Ag} / \mathrm{AgCl}$. The linearity was established over the concentration range of $1-12 \mu \mathrm{g} / \mathrm{mL}$ for both methods in supporting electrolyte and human tissue. No electroactive interferences from the endogenous substances were found in the tissue samples. Mean recovery was $97.5 \%$. The limits of detection and quantification of FA were 0.25 and $0.75 \mu \mathrm{g} / \mathrm{mL}$, respectively. It was concluded that the developed method was accurate, sensitive, precise, reproducible and useful for the quality control of FA in solutions and spiked tissue.
\end{abstract}

Index Terms-Formaldehyde, square wave polarography, tissue, validation.

\section{INTRODUCTION}

Formaldehyde (FA) (Fig. 1) is a colorless solution with pungent smell. $37 \%$ formaldehyde water solution is called formalin. People who inhale formaldehyde gas get congested and have breathing difficulty in some sever cases [1]. It is a well-known skin sensitizer and is a widely used preservative in cosmetics, metalworking fluid, textile, paper products, etc. FA is present in one of three sources: as free FA particularly in

Manuscript received April 15, 2016.

Bilal Y1lmaz is with Department of Analytical Chemistry, Faculty of Pharmacy, Ataturk University, 25240, Erzurum, Turkey

Ali Asc1 is with Department of Pharmaceutical Chemistry, Faculty of Pharmacy, Ataturk University, 25240, Erzurum, Turkey.

Kaan Kucukoglu is with Department of Toxicology, Faculty of Pharmacy, Ataturk University, 25240, Erzurum, Turkey

Mevlut Albayrak was with Department of Pathology, Faculty of Medicine, Ataturk University, 25240, Erzurum, Turkey. He is now with Medical Laboratory Department, Health Services Vocational Training School, Atatürk University, 25070, Erzurum, Turkey

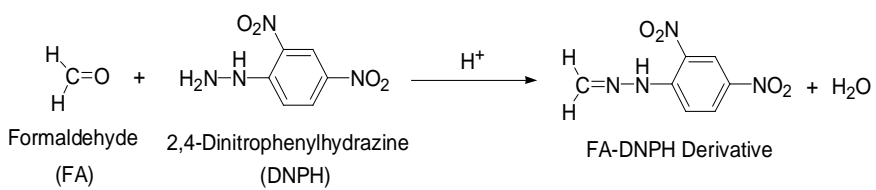

Fig. 1. Proposed mechanism for the reaction of formaldehyde (FA) with 2,4-Dinitrophenyl-hydrazine (DNPH).

cosmetics, shampoos and hair care products, as FA donated from a FA-releasing preservative, and as FA resins. The incidence of FA sensitivity varies greatly. Most of the reported papers ranged from $0.9 \%$ to $19.2 \%$. The incidence of FA allergy in patients with cosmetic dermatitis was estimated to be $1.3 \%$ 9.4\%.1 Cosmetic sensitization to FA is considered to be the most frequently encountered etiology for FA allergy, followed by occupational sensitization [2]. However, FA allergy is sometimes unsuspected by the contact dermatitis specialists. The source of sensitization is frequently unidentifiable as history from the patients is often non-informative. The determination of a positive FA patch test reaction is difficult and relies on the identification of FA sources in the patient's environment. The prognosis of a FA-sensitive patient is poor if the sources of FA could not be eliminated.

Several methods have been reported for the determination of FA including high-performance liquid chromatography (HPLC) method following a derivatization reaction with 2,4-dinitrophenylhydrazine (DNPH) [3]. The technique has been reported for analyses of cosmetics [4], tap water [5], fish-paste products [6], natural gas and oil combustion products [7], aqueous extracts, and model mixtures simulating foods [8]. Hyphenated techniques such as GC-MS and LC-MS/MS can be used as a confirmatory technique. GC-ECD method uses pentafluorobenzyl hydroxylamine to form oxime derivatives of aldehydes in an aqueous solution at $\mathrm{pH} 4$. The derivatives are extracted into hexane and analyzed by GC-ECD (detection limit approximately $<1 \mu \mathrm{g} / \mathrm{L}$ ). For GC-MS, a derivative is extracted from aqueous solution using a suitable solvent such as toluene. Although the GC-MS method has better specificity, the GC-MS method offers a detection limit approximately $10 \mu \mathrm{g} / \mathrm{L}$, inferior to the HPLC method. LC-MS/MS can also be done. The detection limit is $20 \mu \mathrm{g} / \mathrm{L}$, because the MS/MS interferences are 
eliminated. Two reports have been published for the analysis of FA in pharmaceutical products, enteric coating of hard gelatin capsules [9], and injectibles [10].

There are some problems encountered in using such methods. Chromatographic methods are relatively slow and expensive and they require derivatization or time consuming extraction procedures. Thus, the use of simpler, faster and less expensive, but still sensitive electrochemical techniques can be considered as a useful alternative. The polarographic techniques present some advantages in relation to many other analytical techniques. Progress obtained with pulse techniques have increased the range of practical applications of polarography by enabling determinations of electroactive species at lower concentrations. When compared to chromatography, the polarographic procedures have several advantages such as their low cost and short time required for analysis. On the other hand, electroanalytical methods offer useful applications in kinetic and equilibria studies, much more than HPLC which often can perturb equilibria in the reaction mixture.

The development of a new method capable of determining drug amount in standard solutions or biological fluids is important. Electroanalytical techniques have been used for the determination of a wide range of drug compounds with the advantages that there are, in most, instances no need for derivatization and that these techniques are less sensitive to matrix effects than other analytical techniques. Additionally, application of electrochemistry includes the determination of electrode mechanism. Redox properties of drugs can give insights into their metabolic fate or their in vivo redox processes or pharmacological activity. Despite the analytical importance of the electrochemical behaviour and oxidation mechanism of FA, no report has been published on the polarographic study of the electrochemical oxidation of FA in spiked human tissue.

The goal of this work was the development of new polarographic methods for the direct determination of FA in standard solutions and spiked human tissue samples without any time-consuming extraction or evaporation steps prior to drug assay. This paper describes fully validated, simple, rapid, selective and sensitive procedures for the determination of FA employing square wave polarography at mercury electrode. Also, this work was also aimed to study the polarographic behavior and oxidation mechanism of FA using cyclic and SWP techniques.Helpful Hints

\section{EXPERIMENTAL}

\section{Chemicals, reagents and analytical conditions}

FA (37\% solution in water) and 2,4-Dinitrophenyl-hydrazine (DNPH) were obtained from Sigma (St. Louis, MO, USA). Distilled water was prepared as required by using aquaMAX ${ }^{\mathrm{TM}}$ ultra, Young instrument (Korea) ultrawater purification system. Human tissue samples were obtained from Department of Pathology, Erzurum, Turkey.

A stock solution of $50 \mu \mathrm{g} / \mathrm{mL}$ was prepared by dissolving the compound in $0.25 \mathrm{M}$ acetate buffer at $\mathrm{pH}$ 5.0. Standard solutions were prepared by serial dilution of the stock solution with selected supporting electrolyte. The calibration curve for SWP analysis were constructed by plotting the peak current against the FA concentration. The ruggedness and precision were checked at different days, within day and between days. Relative standard deviations were calculated to check the ruggedness and precision of the method [11]. The precision and accuracy of analytical methods are described in a quantitative fashion by the use of relative errors (bias \%). One example of relative error is the accuracy, which describes the deviation from the expected results. All solutions were kept in the dark in a refrigerator and were used within several hours to avoid hydrolysis. However, voltammograms of the sample solutions recorded $48 \mathrm{~h}$ after preparation did not show appreciable change in assay values.

Voltammetric measurements were obtained with Gamry Potentiostat Interface 1000 controlled with software PHE 200 and PV 220. A three electrode cell system was used a static mercury drop electrode system (BAS $100 \mathrm{~W} / \mathrm{B}$ ), including a hanging mercury drop working electrode, a platinum-wire auxiliary electrode and an $\mathrm{Ag} / \mathrm{AgCl}(\mathrm{KCl} 3 \mathrm{M}$, BAS) electrode as the reference electrode. All $\mathrm{pH}$ measurements were made with Model $538 \mathrm{pH}$ meter (WTW, Austria), calibrated with standard buffers (Fixanal, Riedel-deHaen, Germany) at room temperature. All measurements were carried out at ambient temperature of the laboratory $\left(22-25{ }^{0} \mathrm{C}\right)$. For analytical application, the following parameters being employed: SWP pulse amplitude $25 \mathrm{mV}$, frequency $15 \mathrm{~Hz}$, potential step $4 \mathrm{mV}$.

\section{Preparation of stock standard solutions}

The stock solution of FA $(50 \mu \mathrm{g} / \mathrm{mL})$ was prepared and diluted with a $0.25 \mathrm{M}$ acetate buffer at $\mathrm{pH} 5.0$ to give standard solutions of $1-12 \mu \mathrm{g} / \mathrm{mL}$. Standard calibration samples were prepared daily by spiking $1.0 \mathrm{~mL}$ of drug-free human tissue with $1 \mathrm{~mL}$ of appropriate FA standard solutions to achieve final concentrations of $1-12 \mu \mathrm{g} / \mathrm{mL}$ for tissue.

\section{Preparation of quality control samples}

The concentrations of FA were 3,7 and $11 \mu \mathrm{g} / \mathrm{mL}$ in human tissue to represent low, middle and high quality controls, respectively. Appropriate volumes from stock solution of FA were added to normal human tissue to get low, middle and high quality control samples and stored at $-20^{\circ} \mathrm{C}$. The quality control samples were taken out from storage for analysis to determine intra- and inter-day precision and accuracy.

\section{Analysis of spiked tissue samples}

Tissue samples were obtained from the pathology laboratory. And a part of of biopsy sample which is not used for pathological assesment was used for blank tissue. Blank tissue homogenates were prepared at a concentration of $10 \%(\mathrm{w} / \mathrm{v})$ in acetate buffer (0.25 M, pH: 5.0) using an Ultra-Turrax homogenizer after grinding in liquid nitrogen. 1 $\mathrm{ml}$ tissue homogenate sample was spiked into centrifuge tube. Then, $1 \mathrm{ml} \mathrm{FA}$ and $0.5 \mathrm{~mL}$ DNPH solutions were added. After vortex mixing for $5 \mathrm{~s}$, tissue sample was waited for $15 \mathrm{~min}$ at 60 ${ }^{0} \mathrm{C}$. Then, $3.5 \mathrm{~mL}$ of $0.25 \mathrm{M}$ acetate buffer at $\mathrm{pH} 5.0$ was added. 
The concentration of FA was varied in the range of $1-12 \mu \mathrm{g} / \mathrm{mL}$ in human tissue sample.

\section{RESULT}

\section{Effect of supporting electrolyte}

Polarographic response of FA was studied in various supporting electrolytes in the $\mathrm{pH}$ range 3.0-10.0. FA yielded a single oxidation wave in supporting electrolytes such as $0.25 \mathrm{M}$ phosphate buffer between $\mathrm{pH} 2$ and 12, $0.04 \mathrm{M}$ Britton-Robinson buffer between $\mathrm{pH} 2$ and 12, $0.25 \mathrm{M}$ acetate buffer between $\mathrm{pH} 3.5$ and 5.7 were used as the supporting electrolytes. However, a best-defined oxidation peak was obtained in acetate (HAc-NaAc) buffer. Therefore, this work was selected the HAc-NaAc buffer as supporting electrolyte.

\section{Effect of $p H$ values}

The effect of $\mathrm{pH}$ values in the $\mathrm{pH}$ range 3.5-5.7 on both peak current and peak potential of the oxidation wave of FA was examined in the HAc-NaAc buffer. It showed that the peak current increased gradually upon increasing $\mathrm{pH}$ values from 3.5 to 5.0 and remained nearly unchanged from 5.0 to 5.7, following which a sharp decrease in the current response upon increasing $\mathrm{pH}$ values from 5.0 to 5.7 was observed. On the other hand, the peak potential shifted with $\mathrm{pH}$ values from 3.5 to 5.7 toward the positive direction. Therefore, the HAc-NaAc buffer of $\mathrm{pH} 5.0$ was selected.

\section{Effect of buffer concentration}

The effect of the total concentration of HAc-NaAc ( $\mathrm{pH} 5.0$ ) buffer was tested over the range 0.025-0.40 M. The peak current increased gradually upon the HAc-NaAc concentration increasing from 0.025 to $0.15 \mathrm{M}$ and then reached a current plateau until $0.40 \mathrm{M}$, while the peak potential Ep shifted positively from -0.11 to $-0.17 \mathrm{~V}$. The total concentration of the HAc-NaAc (pH 5.0) buffer used in this experiment was $0.25 \mathrm{M}$, consisting of $0.083 \mathrm{M} \mathrm{HAc}$ and $0.167 \mathrm{M} \mathrm{NaAc}$.

\section{Electrochemical behavior of FA}

Successive cyclic voltammograms of FA obtained in HAc-NaAc buffer of $\mathrm{pH} 5.0$ at a scan rate of $100 \mathrm{mV} / \mathrm{s}$ are shown in Fig. 2. The cyclic voltammogram of $20 \mu \mathrm{g} / \mathrm{mL}$ FA exhibits a single anodic peak, The study of the influence of scan rate shows that the peak current changes linearly with scan rate. The role of adsorption is further supported by the sharp form of the main anodic peak and by the dependence of the peak current on scan rate (v). For diffusion current the plot of log ip as a function of $\log \mathrm{v}$ should have a slope of 0.5 and for a purely adsorption current a slope of 1.0 [12]. The regression of log ip vs log $\mathrm{v}$ gave a slope value of 0.48 , indicating that the oxidation current is of diffusional nature. On the other hand, as

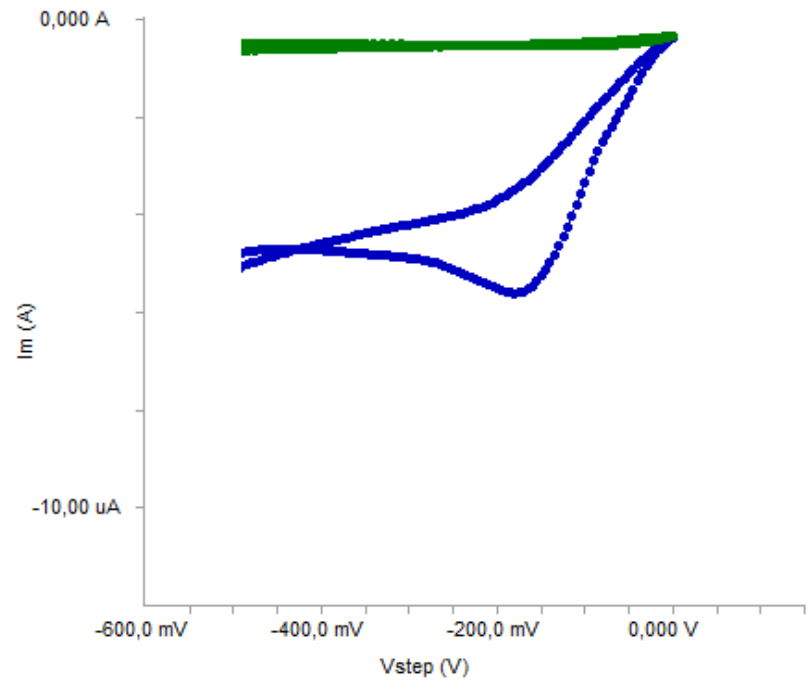

Fig. 2. Cyclic polarogram of $20 \mu \mathrm{g} / \mathrm{mL}$ derivatized FA-DNPH in 0.25 $\mathrm{M}$ acetate buffer ( $\mathrm{pH}$ 5.0) at hanging mercury drop working electrode, scan rate: $0.1 \mathrm{~V} / \mathrm{s}$.

scan rate was increased from 10 to $1000 \mathrm{mV} / \mathrm{s}$, the peak potential shifted toward more positive potential as expected for an irreversible oxidation process [13]. The value of $\alpha$, product of transfer coefficient and number of electrons transferred in the rate-determining step, was determined from treatment (log i vs E) of the polarographic curves. The value obtained (0.41) shows the total irreversibility of the electron transfer process. It was also demonstrated by the linear relationship obtained between the peak potential (Ep) and the logarithm of scan rate in the range $10-1000 \mathrm{mV} / \mathrm{s}$. Based on the polarographic behavior of FA, a quantitative method was developed. To select the best electrochemical method, the anodic peak obtained by cyclic and SWP were compared with each other. In order to develop a polarographic method for determination of the FA, we selected the SWP technique, since the peaks were sharper and better defined at lower concentration of FA than those obtained by cyclic polarography with a lower background current, resulting in improved resolution. SWP is effective and rapid electroanalytical techniques with well-established advantages, including good discrimination against background currents and low detection and determination limits [14-16].

\section{Validation of the method}

The validation was carried out by establishing specificity, linearity, accuracy, precision, limit of detection (LOD), limit of quantification (LOQ), ruggedness, recovery according to $\mathrm{ICH}$ Q2B recommendations [17].

\section{Linearity}

Standard solutions were prepared as 1-12 $\mu \mathrm{g} / \mathrm{mL}(1,2,4,6$, 8, 10 and $12 \square \mathrm{g} / \mathrm{mL}$ ) for SWP (Fig. 3). Calibration curve was constructed for FA standard by plotting the concentration of 


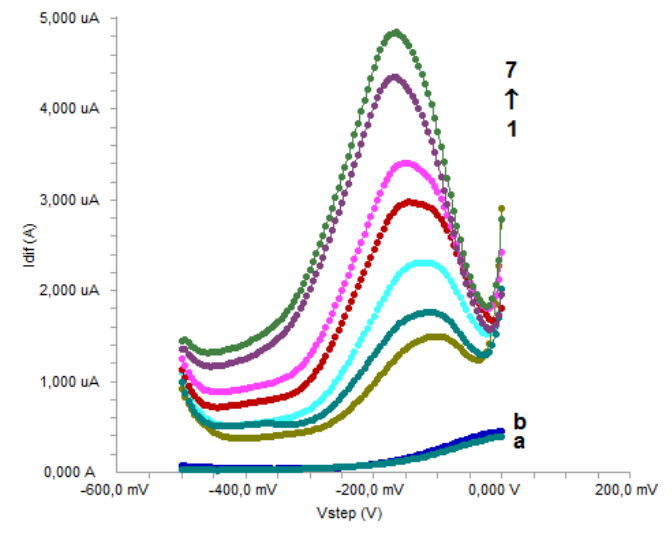

Fig. 3. Square wave polarograms obtained for the determination of FA in spiked tissue (a: Supporting electrolyte, b: FA, (1) $1 \mu \mathrm{g} / \mathrm{mL}$, (2) 2 $\mu \mathrm{g} / \mathrm{mL}$, (3) $4 \mu \mathrm{g} / \mathrm{mL}$, (4) $6 \mu \mathrm{g} / \mathrm{mL}$, (5) $8 \mu \mathrm{g} / \mathrm{mL}$, (6) $10 \mu \mathrm{g} / \mathrm{mL}$, (7) 12 $\mu \mathrm{g} / \mathrm{mL}$ derivatized FA-DNPH.

compound versus peak current responses. The calibration curve was evaluated by its correlation coefficients. The correlation coefficients (r) of all the calibration curves were consistently greater than 0.99. The linear regression equations were calculated by the least squares method using Microsoft Excel ${ }^{\circledR}$ program and summarized in Table I.

TABLE I: REGRESSION DATA OF THE CALIBRATION LINES FOR QUANTITATIVE DETERMINATION OF FA.

\begin{tabular}{lcc}
\hline \hline Parameters & \multicolumn{2}{c}{ SWP } \\
\hline \hline & \multicolumn{2}{c}{ Supporting electrolyte } \\
Tissue & -0.15 & -0.16 \\
Measured potential $(\mathrm{V})$ & $1-12$ & $1-12$ \\
Linearity $(\mu \mathrm{g} / \mathrm{mL})$ & 0.2931 & 0.3094 \\
Slope & 1.2411 & 1.1177 \\
Intercept & 0.998 & 0.994 \\
$\mathrm{R}$ & 0.0586 & 0.0234 \\
$\mathrm{~S}_{\mathrm{a}}$ & 0.544 & 0.643 \\
$\mathrm{~S}_{\mathrm{b}}$ & 0.20 & 0.25 \\
LOD ( $\mu \mathrm{g} / \mathrm{mL})$ & 0.60 & 0.75 \\
LOQ ( $\mu \mathrm{g} / \mathrm{mL})$ & 2.32 & 5.94 \\
Precision (RSD\%) & -2.29 & 4.70 \\
Accuracy (\% relative error) & 1.78 & 2.73 \\
Repeatability of peak current (RSD\%) & $\mathrm{a}$ \\
Repeatability of peak potential (RSD\%) & 1.01 & 2.86 \\
Reproducibility of peak current (RSD\%) & 2.14 & 3.14 \\
Reproducibility of peak potential (RSD\%) & 2.13 & 2.96 \\
& &
\end{tabular}

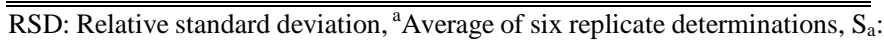
Standard deviation of intercept of regression line, $\mathrm{S}_{\mathrm{b}}$ : Standard deviation of slope of regression line, R: Coefficient of correlation, LOD: Limit of detection, LOQ: Limit of quantification.

\section{Accuracy and precision}

Accuracy of the assay methods was determined for both intra-day and inter-day variations using the six times analysis of the quality control (QC) samples. Repeatability refers to the use of the analytical procedure within a laboratory over a short period of time that was evaluated by assaying the QC samples during the same day. Intermediate precision was assessed by comparing the assays on different days (2 days). The intra-day accuracy ranged from $-2.29 \%$ to $4.70 \%$ and precision from $2.32 \%$ to $5.94 \%$. The results obtained from intermediate precision (inter-day) also indicated a good method precision.

\section{Limits of detection (LOD) and quantification (LOQ)}

The LOD and LOQ of FA by the proposed methods were determined using calibration standards. LOD and LOQ values were calculated as $3.3 \sigma / \mathrm{S}$ and $10 \sigma / \mathrm{S}$, respectively, where $\mathrm{S}$ is the slope of the calibration curve and $\sigma$ is the standard deviation of $y$-intercept of regression equation $(n=3)$ [17]. The LOD and LOQ values of the method was summarized in Table 1.

\section{Ruggedness}

In this study, the SWP determination of FA was carried out by a different analyst in same instrument with the same standard. The results showed no statistical differences between different operators suggesting that the developed method was rugged.

\section{Stability}

To evaluate the stability of FA, standard solutions were prepared separately at concentrations covering the low, medium and higher ranges of calibration curve for different temperature and times. These solutions were stored at room temperature, refrigeratory ( $4 \square \mathrm{C}$ ) and frozen (-20 $\square \mathrm{C}$ ) temperature for $24 \mathrm{~h}$ and $72 \mathrm{~h}$. Stability measurements were carried out with SWP method. The results were evaluated comparing these measurements with those of standards and expressed as percentage deviation and FA was found as stable at room temperature, 4 and -20 $\square \mathrm{C}$ for at least $72 \mathrm{~h}$.

\section{Recovery}

The optimized procedure was successfully applied for the determination of FA in spiked human tissue samples. No extraction steps other than the centrifugal protein separation were required prior to the assay of FA. Fig. 3 illustrates the response of successive standard additions of FA. Calibration equation parameters and necessary validation data were shown in Table I. Obtained recovery results of spiked human tissue samples were given in Table II. 
TABLE II RECOVERY OF FA IN HUMAN TISSUE

\begin{tabular}{cccc} 
Added $(\mu \mathrm{g} / \mathrm{mL})$ & Found & \% Recovery & \% RSD $^{\mathrm{b}}$ \\
\hline 1 & $0.93 \pm 0.06$ & 93.0 & 6.45 \\
2 & $1.99 \pm 0.11$ & 99.5 & 5.53 \\
4 & $3.97 \pm 0.27$ & 99.3 & 6.80 \\
6 & $5.89 \pm 0.52$ & 98.2 & 8.83 \\
8 & $7.86 \pm 0.35$ & 98.3 & 4.45 \\
10 & $9.91 \pm 0.41$ & 99.1 & 4.14 \\
12 & $11.7 \pm 0.68$ & 97.5 & 5.81 \\
\hline \hline
\end{tabular}

$\mathrm{SD}^{\mathrm{a}}$ : Standard deviation of three replicate determinations, RSD: Relative standard deviation, ${ }^{\mathrm{b}}$ Average of three replicate determinations, $\mathrm{SD}^{\mathrm{a}}$ : Standard deviation of three replicate determinations,RSD: Relative standard deviation

\section{DISCUSSION}

FA is a potential mutagen and carcinogen, which also can result in muscle toughening and water loss in aquatic products $[18,19]$. However, it is often used illegally in the food processing industry because the addition of FA can prolong the storage life of some foodstuffs and give a face-lift by changing their color and smell. Moreover, enzymatic degradation of trimethylamine oxide in aquatic products during postmortem storage also can generate dimethylamine and FA [20-22]. FA is a small molecule and has one carbon and one heterogeneous oxygen atom. This molecule is not readily amenable to gas chromatography with flame ionization detection. Also, FA is not easily ionizable and cannot be easily analyzed by mass spectrometry. The analysis of formaldehyde is commonly achieved by a HPLC method following a derivatization reaction with 2,4-dinitrophenylhydrazine [3]. During method development, it became evident that FA was very sensitive to matrix effects during the derivatization process in tissue. Sample preparation techniques, such as liquid-liquid extraction was used in order to minimise matrix suppression effects.

HPLC-UV method sensitivity is not enough for the determination of FA in tissue. For this reason, DNPH was chosen as a chromagenic derivatization reagent. In this study, the purpose of the derivatization reaction is the raise of sensitivity thus the possibility of working in low concentrations has been occurred. FA was extracted from human plasma with a solid phase extraction procedure in reported in other papers [20, 23, 24]. This method is also the most comprehensive method which can extract FA in a single extraction procedure. The mean recovery is better for tissue than other papers [20,23,24].

Luo et al. [25] have reported HPLC method with fluorescence detection for the analysis of FA in human plasma. The calibration curve of the method was linear for FA in the range $1.65-16 \mu \mathrm{g} / \mathrm{mL}$. Intra- and inter-day precision values were lower than $8.0 \%$. The mean recovery of FA was $93.3 \%$. The LOQ of method was found $0.87 \mu \mathrm{g} / \mathrm{mL}$. Detection using HPLC method with fluorescence detection would be a more sensitive approach but is costly and not yet available for every laboratory.

Voltammetry has been recently proposed as a promising new analytical method for electrochemical detection of drugs. Owing to the high sensitivity, low cost, simplicity of instrumentation and short analysis time voltammetric techniques are important methods for pharmaceutical analysis [26,27].

Polarographic determination of FA at hanging mercury drop working electrode in tissue samples was referred to the regression equation. The mean relative standard deviation (RSD) was 5.94\% using the proposed SWP method for the polarographic analysis. The validity of the proposed procedure applied to tissue samples was also assured by the recovery of standard additions. A mean recovery of $97.5 \%$ with RSD of 4.70 was obtained. The results of the drug analysis obtained from the proposed method are in close agreement with the claimed value.

\section{CONCLUSION}

The novel electro-analytical method involving SWP at dropping mercury electrode was proposed to determine FA content in spiked tissue samples. The method presented for the quantitative determination of FA allowed the accurate determination and was found to be rapid, simple and highly sensitive. The main advantage of such a procedure is the possibility to determine the concentration of the active component directly from spiked tissue samples without any previous treatment, such as extraction, clean-up, derivatization or pre-concentration which are tedious, time consuming and also polluting. Therefore, the proposed method can possibly be used for the determination of FA in tissue samples as well as for clinic control laboratories.

\section{REFERENCES}

[1] W. D Kerns, K. L. Pavlov, D. J. Donofrio, E. J. Gralla, and J. A. Swenberg, "Carcinogenicity of formaldehyde in rats and mice after long-term inhalation exposure," Cancer Research, vol. 4, pp. 4382-4392, September1983.

[2] A. F. Fransway, "The problem of preservation in the 1990s: i. statement of the problem, solution(s) of the industry, and the current use of formaldehyde and formaldehyde-releasing biocides," American Journal of Contact Dermatitis, vol. 2, pp. 6-23, March 1991. http://dx.doi.org/10.1097/01634989-199103000-00004

[3] G. Lun and L.C. Hellwing, Handbook of Derivatization Reactions for HPLC, Wiley-Interscience Publication, 1998.

[4] P. W. Wu, C. C. Chang, and S. S. Chou, "Determination of formaldehyde in cosmetics by hplc method and acetylacetone method," Journal of Food and Drug Analysis, vol. 11, no. 1, pp. 8-15, 2003.

[5] J. Lehotay and K. Hromulakova, "Hplc determination of trace levels of aliphatic aldehydes $\mathrm{c}_{1}-\mathrm{c}_{4}$ in river and tap water using on-line preconcentration," Journal of Liquid Chromatography, vol. 17, no. 3, pp. 579-588, 1994. http://dx.doi.org/10.1080/10826079408013161

[6] K. Kido, T. Sakuma, and T. Watanabe, "Gas chromatographic analysis of formaldehyde in fish-paste products," Eisei Kagaku, vol. 26, no. 5, pp. 224-28, 1980. http://dx.doi.org/10.1248/jhs1956.26.224

[7] H. J. Gotze and H. Fresenius, "Determination of aldehydes and ketones in natural gas combustionin the ppb range by high-performance liquid chromatography," Analytical Chemistry, vol. 335, pp. 286-288, 1989. http://dx.doi.org/10.1007/BF00472589

[8] A. L. Pertsovskii and L.M. Kremko, "Gas chromatographic determination of trace amounts of formaldehyde in aqueous extracts and model mixtures simulating foods," Analytical Chemistry, vol. 40, no. 6, pp. 1115-1118, 1985.

[9] E. Pina, A. T. Sousa, and A. P. Brojo, "Hplc method development and validation for formaldehyde in enteric coating of hard gelatin capsules," Journal of Liquid Chromatography, vol. 18, no. 13, pp. 2683-2693, 1995. 
http://dx.doi.org/10.1080/10826079508009318

[10] Y. Kato, K. Akiyama, S. Kohchi, S. Shinhachiro, Y. Masaaki, and T. Yokoyama, "Micoanalysis of aldehydes in $1 \%$ lauromacrogol injections," Byoin Yakugaku, vol. 15, no. 5, pp. 332-335, 1989.

[11] M. E. Swartz and I. S. Krull, Analytical Method Development and Validation, Marcel Dekker, New York, USA, 1997.

[12] D. K. Gosser, Cyclic Voltammetry, VCH, New York, USA, 1994.

[13] A. J. Bard and L. R. Faulkner, Electrochemical Methods : Fundamentals and Applications, 2 nd ed., Wiley, New York, USA, 2001.

[14] J. Wang, Analytical Electrochemistry, 2nd ed., Wiley/VCH Publishers, New York, USA, 2000. http://dx.doi.org/10.1002/0471228230

[15] P. T. Kissenger and W. R. Heineman, Laboratory Techniques in Electroanalytical Chemistry, 2 nd ed., Marcel Dekker, New York, USA, 1996.

[16] J. Wang, Electroanalytical Techniques in Clinical Chemistry and Laboratory Medicine, VCH Publishers, New York., USA, 1996.

[17] The European Agency for the Evaluation of Medicinal Products ICH Topic Q2B Note for Guideline on Validation of Analytical Procedures: Methodology GPMP/ICH/281/95-1996.

[18] Z. Li, H. Ma, H. Lu, and G. Tao, " Determination of formaldehyde in foodstuffs by flow injection spectrophotometry using phloroglucinol as chromogenic agent,” Talanta, vol. 74, no. 4, pp. 788-792, January 2008. http://dx.doi.org/10.1016/j.talanta.2007.07.011

[19] J. Li, J. Zhu, and l. Ye, "Determination of formaldehyde in squid by highperformance liquid chromatography,” Asia Pacific Journal of Clinical Nutrition, vol. 16, pp. 127-130, 2007.

[20] F. Bianchi, M. Careri, M. Musci, and A. Mangia, "Fish and food safety: Determination of formaldehyde in 12 fish species by SPME extraction and GC-MS analysis," Food Chemistry, vol. 100, no. 3, pp. 1049-1053, 2007.

http://dx.doi.org/10.1016/j.foodchem.2005.09.089

[21] I. E. Bechmann, "Determination of formaldehyde in frozen fish with formaldehyde dehydrogenase using a flow injection system with an incorporated gel-filtration chromatography column,” Analytica Chimica Acta, vol. 320, no.2-3, pp. 155-164, February 1996. http://dx.doi.org/10.1016/0003-2670(95)00561-7

[22] M. K. Nielsen and B. M. Jorgensen, “ Quantitative relationship between trimethylamine oxide aldolase activity and formaldehyde accumulation in white muscle from gadiform fish during frozen storage," Journal of Agricultural and Food Chemistry, vol. 52, no. 12, pp. 3814-3822, 2004. http://dx.doi.org/10.1021/jf035169l

[23] M. T. Oliva-Teles, P. Paiga, C. M. Delerue-Matos, and M. C. M. Alvim-Ferraz, "Determination of free formaldehyde in foundry resins as its 2,4-dinitrophenylhydrazone by liquid chromatography," Analytica Chimica Acta, vol. 467, no. 1-2, pp. 97-103, September 2002. http://dx.doi.org/10.1016/S0003-2670(02)00130-7

[24] Q. Wang, J. O’Reilly, and J. Pawliszyn, "Determination of low-molecular mass aldehydes by automated headspace solid-phase microextraction with in-fibre derivatization,” Journal of Chromatography A, vol. 1071, no. 1-2, pp. 147-154, April 2005. http://dx.doi.org/10.1016/j.chroma.2004.09.031

[25] W. Luo, H. Li, Y. Zhang, C. Y.W. Ang, "Determination of formaldehyde in blood plasma by high-performance liquid chromatography with fluorescence detection," Journal of Chromatography B, vol. 753, no. 2, pp. 253-257, April 2001. http://dx.doi.org/10.1016/S0378-4347(00)00552-1

[26] G.B. El-Hefnawey, I.S. El-Hallag, E.M. Ghoneim, and M.M. Ghoneim, "Voltammetric behavior and quantification of the sedative-hypnotic drug chlordiazepoxide in bulk form, pharmaceutical formulation and human serum at a mercury electrode," Journal of Pharmaceutical and Biomedical Analysis, vol. 34, no. 1, pp. 75-86, January 2004. http://dx.doi.org/10.1016/j.japna.2003.08.008

[27] P. Corti, G. Corbini, P. Gratteri, S. Furlanetto, and S. Pinzauti, "Determination of some quinolones in tablets, human plasma and urine by differential-pulse polarography," International Journal of Pharmaceutics, vol. 111, no. 1, pp. 83-87, October 1994. http://dx.doi.org/10.1016/0378-5173(94)90404-9

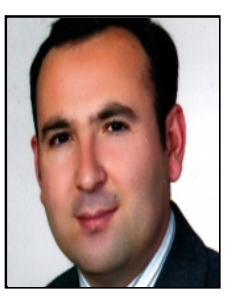

Bilal Yılmaz was born in Denizli, Turkey in 1975. He is an associate professor in Department of Analytical Chemistry, Faculty of Pharmacy, Ataturk University, Erzurum, Turkey since 2013. His research interests include analytical chemistry, GC-MS, HPLC, spectroscopy and electrochemistry.

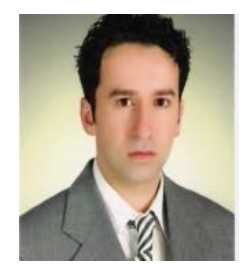

Ali Ascı was born in Isparta, Turkey in 1980. He is an assistant professor in Department of Pharmaceutical Toxicology, Faculty of Pharmacy, Ataturk University, Erzurum, Turkey since 2014. His research interests include pharmaceutical toxicology and HPLC.

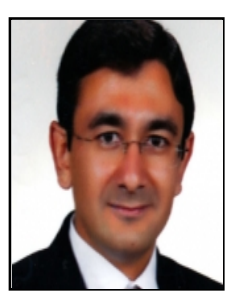

Kaan Kucukoglu was born in İzmir, Turkey in 1971. $\mathrm{He}$ is an assistant professor in Department of Pharmaceutical Chemistry, Faculty of Pharmacy, Ataturk University, Erzurum, Turkey since 2010. His research interests include pharmaceutical chemistry and HPLC.

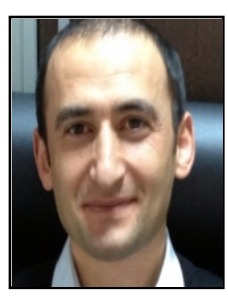

Mevlut Albayrak was born in Erzurum, Turkey in 1979. He studied in Department of Pathology, Faculty of Medical, Ataturk University, Erzurum, Turkey from June 2001 to February 2016 as the immunohistochemistry of specialist. He is now an assistant professor in Medical Laboratory Department, Health Services Vocational Training School, Atatürk University, Erzurum, Turkey. His research interests include analytical chemistry, HPLC and pathology. 